\title{
$\mathrm{PPG}$ 를 이용한 심혈관 질환 예측 시스템의 설계 및 구현
}

\author{
송제민 ${ }^{*}$, 진계환**, 서성보**, 박정석****, 이상복**, 류근호* \\ 충북대학교 데이터베이스 및 바이오인포매틱스 연구실 ${ }^{*}$ 남부대학교 방사선학과**, 한국전자통신연구원(ETRI) ${ }^{* * *}$, \\ 충주대학교 의료정보공학과 ${ }^{* * *}$
}

\section{Design and Implementation of a Prediction System for Cardiovascular Diseases using PPG}

\author{
Jeminsong*, Gyehwan Jin ${ }^{* *}$, Sungboseo ${ }^{* * *}$, Jeongseok Park ${ }^{* * * *}$, Sangbock Lee ${ }^{* *}$, Keunho Ryu* \\ Database and Bioinformatics Laboratory, Chungbuk Nat'l University ${ }^{* *}$, Dept. of Radiology, Nambu University ${ }^{* *}$, Electronics \\ and Telecommunications Research Institute(ETRI) ${ }^{* * *}$, Dept. of Medical Information Engineearing, Chungju Nat'l University ${ }^{* * * *}$
}

\section{요 야}

광용적맥파(photoplethysmogram, PPG)는 심장의 수축과 이완으로 변화하는 혈액용적(blood volume)과 혈액내의 헤모글로빈에 흡수되는 빛의 양의 선형적 관계를 이용하여 신호를 획득하는 방법이다. 본 논문에서는 PPG 센서를 이 용하여 질환 예측을 할 수 있는 시스템을 제안하였다. 본 시스템은 PPG 센서를 이용하여 심박수의 변이를 살펴볼 수 있는 심박수 변이 분석과 이전 심박수와 이후 심박수를 구분지어 그래프로 표현하는 심박수 분포를 보여준다. 또한 심 박수를 스펙트럼 분석하여 자율신경계 균형도, 가속도 맥파로부터 혈관 상태를 분석하여 심혈관 질환을 조기 예측하는 개인용 컴퓨터 기반의 시스템을 설계하고 구현하였다.

중심단어: 심박동 변화, PPG, APG(acceleration plethysmogram)

\begin{abstract}
Photoplethysmogram(PPG) is the method to obtain the biomedical signal using the linear relationships between the blood volume for changing the cardiac contraction and relaxation and the amount of light for absorbing the hemoglobin in the blood. In this paper, we proposed the analyzed results which show the heart rate variability and the distribution of heart rate for before and after using PPG. Moreover, this paper designed and implemented the system based on personal computer to predict cardiovascular disease in advance using the analyzed results for the autonomic balance from taking the spectral analysis of heart rate and the state of the blood vessel for analyzing APG(acceleration plethysmogram).
\end{abstract}

Key Words : Heart Rate Variability, PPG, APG(acceleration plethysmogram) 


\section{I. 서론}

심장혈관계(cardiovascular system)는 신체의 혈액 순 환을 담당하는 기관인 심장과 혈관으로 구성되어 있 고 심장질환으로는 심부전, 고혈압성 심장질환, 부정 맥, 판막질환, 선천성 심장질환, 심근경색증 등이 있고 혈관질환에는 고지혈증, 동맥경화증 등이 있다 ${ }^{[1]}$. 심장 혈관계에 의한 사망은 WHO(World Health Organization) 의 국제질병사인분류체계에 따른 주요 사망원인별 사 망률에 따른 통계청의 2009년 사망원인의 2위를 차지 하였다 ${ }^{[2]}$.

심혈관질환을 진단방법으로 초음파, 자기공명영상, 핵의학검사, 전산화단층 혈관조영술, 디지털감산혈관 조영술(Digital subtraction angiography) 등 영상기법을 이용하고 있지만 ${ }^{[3]}$ 고비용, 장시간측정, 카테터를 이용 한 침습적방법, 방사선에 피폭과 같은 단점을 가지고 있다. 광용적맥파(photoplethysmogram, PPG)는 심장 수 축과 이완으로 변화하는 혈액용적(blood volume)과 헤 모글로빈에 의해 흡수되는 빛의 양의 선형적 관계를 이용하여 신호를 획득하는 방법이다. 이는 매우 간편 하게 이용할 수 있는 비침습적 방법으로 심혈관질환 조기 예측의 유용성에 대한 연구가 진행되고 있다 ${ }^{[4-9]}$. 심장혈관질환의 고위험군 대상군에서 위팔-발목 맥파 속도는 복부 대동맥 신전성과 유의한 상관관계를 보 이며 연령, 혈압과 더불어 복부대동맥의 경직도를 반 영하는 독립적인 지표이다 ${ }^{[10]}$. 심박수변이도는 외부 환 경 변화나 예상치 못한 자극에 대해 심장이 대처할 수 있는 능력을 간접적으로 관찰하는 비침습적인 방법이 다 $^{[11]}$.

따라서 본 논문에서는 PPG 센서를 이용하여 심박 수 변이 분석과 자율신경계 균형도 분석 그리고 가속 도 맥파 분석을 하였다. 심박수 변이 분석은 심박수를 이전 심박수와 이후 심박수로 구분하여 그래프로 표 현한 결과이고, 자율신경계 균형도 분석은 심박수를 스펙트럼 분석한 결과이다. 또한 가속도 맥파를 이용 해 혈관 상태를 분석하였다. 이 결과를 이용하여 심혈 관질환을 조기 예측하는 개인용 컴퓨터기반의 시스템 을 개발하였다.

\section{II. 시스템 구동원리 및 구성}

PPG 센서를 이용한 실시간 생체신호 모니터링 및 분석 시스템의 구조는 그림 1 과 같이 데이터 수집, 데 이터 분석 및 저장과 분석 결과와 같이 크게 3 단계로 분류된다.

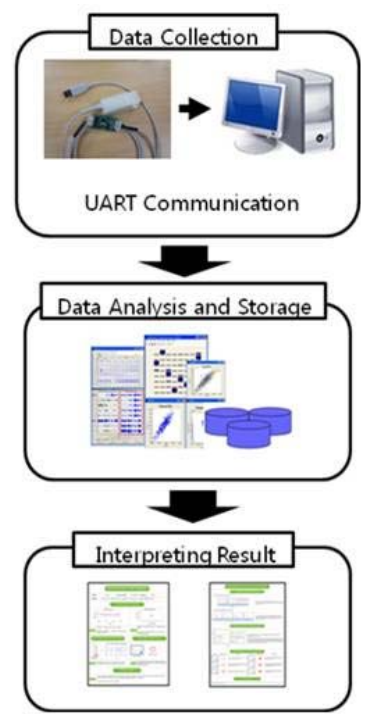

[그림 1] 심혈관질환의 조기예측시스템의 구조

\section{PPG 데이터 획득}

PPG 센서는 손가락에 착용하는 형태로 PC와 통신 을 하여 데이터를 전송하고 수신되는 데이터를 3 5분 정도 수집한다. 본 시스템에 사용된 PPG 센서에서는 사용자의 PPG 데이터, 분당 심박수, 산소포화도, 기타 센서의 상태를 나타내는 데이터로 이루어져 있으며, PPG 센서의 전송 데이터 시트는 그림 2와 같다.

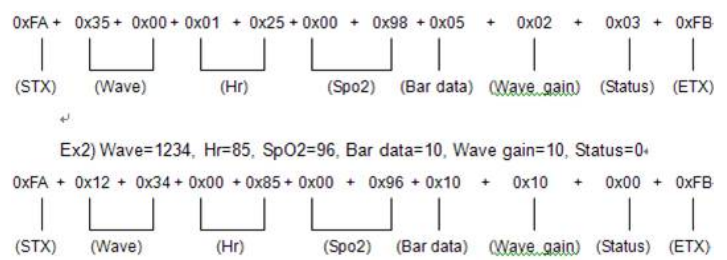

[그림 2] PPG 센서 데이터 시트 
생체신호 데이터 수집은 UART 인터페이스의 USB 통신 및 Bluetooth 형태로 수집이 가능하며, 각 인터페 이스의 특징은 다음과 같다.

\subsection{USB 통신 데이터 수집}

USB 통신 전송 방식은 UART 인터페이스를 사용하 는 PPG 센서를 PC의 USB에 연결하고 $\mathrm{COM}$ 포트를 이용하여 데이터를 수신하는 방식이다. USB로 UART 인터페이스와 통신할 수 있도록 해당 운영체제에 맞 는 드라이버를 설치해 주어야 한다. 이 드라이버는 PPG 센서의 개발 업체에서 지원받았으며, 본 시스템 구현물의 설치 파일에 내장되어 사용되었다. USB 통 신이 가능해진 경우 PC의 특정 포트를 이용하여 센서 는 사용자의 생체신호 데이터를 실시간으로 측정, 전 송하고 본 시스템은 해당 데이터를 수집하는 형태로 구성된다.

\subsection{Bluetooth 통신 데이터 수집}

Bluetooth 통신 전송 방식은 본 시스템에서 사용된 UART 통신 방식의 PPG 센서 모듈을 개조하여 Bluetooth 통신 방식으로 변형하여 사용 가능하다. $\mathrm{COM}$ 포트를 이용한 USB 통신과 다르게 Bluetooth 인 터페이스는 무선 통신을 이용한다. 따라서 큐(Queue) 알고리즘을 이용하여 전송 데이터를 버퍼에 저장하고 일정량이 전송되면 처리하는 방식으로 구현하였다. 개 조 전의 UART 인터페이스의 PPG 센서 모듈은 그림 3 과 같으며, 완성된 Bluetooth 방식의 PPG 센서 모듈은 그림 4,5 와 같다. 그림 4 는 개조된 PPG 센서의 전면 을 나타내며, 그림 5 는 후면을 나타낸다.

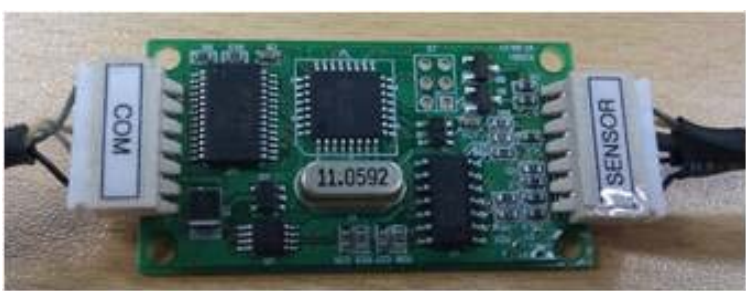

[그림 3] UART 인터페이스 PPG 센서 모듈

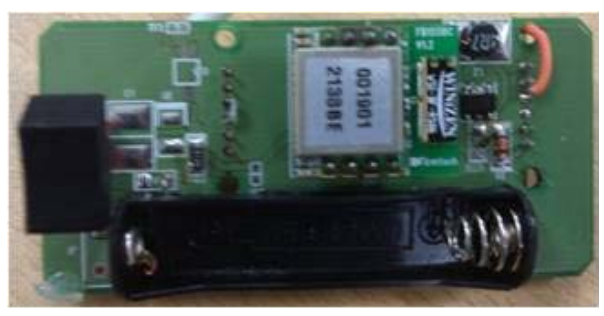

[그림 4] Bluetooth 인터페이스 PPG센서모듈(전)

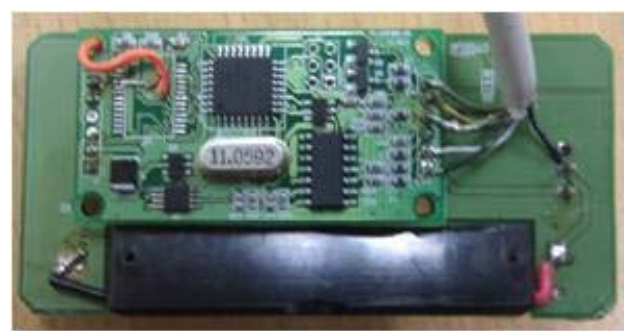

[그림 5] Bluetooth 인터페이스 PPG센서모듈(후)

\section{PPG 신호 분석}

2단계는 수집된 PPG 데이터를 분석하는 단계로 이 루어졌다. 본 논문에서 수집된 생체신호 데이터는 심 박수를 이용한 시간 도메인 분석을 하고 심박수 사이 의 시간 간격을 이용하여 주파수 대역으로 변환하여 이를 분석하는 주파수 도메인 분석을 한다. 또한 PPG 데이터를 2차 미분하여 APG (accelerated plethysmogram) 데이터로 변형하고 이를 이용한 가속도 맥파 파형 분석하였다.

\section{1. 시간 도메인 분석}

수집된 생체신호 데이터 중 시간 도메인 분석과정 은 사용자의 분당 심박수를 시간 그래프로 출력하여 심박수의 변이를 살펴볼 수 있는 심박수 변이 분석과, 심박수를 이전 심박수와 이후 심박수로 구분하여 그 래프로 표현하는 심박수 분포 분석으로 이루어진다. 

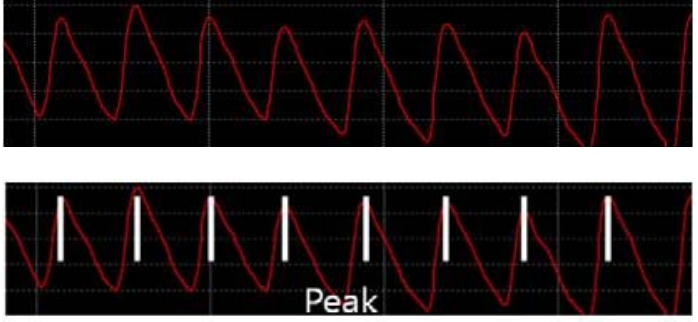

[그림 6] PPG 데이터(상) PPG 데이터의 Peak(하)

분당 심박수를 계산하기 위해서는 심박수를 표현하 는 특정 피크(Peak)를 찾는 단계와 심박수의 분당 총 횟수를 계산하는 단계로 이루어진다. PPG 센서를 이 용한 생체신호의 심박수 파형의 모양은 그림 6(상)과 같이 나타나며, 그림 6(하)과 같이 파형에서 특정 피크 를 찾아내야 한다. 피크를 찾는 과정은 PPG 데이터를 PAA (Piecewise Aggregate Approximation) 기법 ${ }^{[12]}$ 을 적 용한 SAX (Symbolic Aggregate approXimation) 알고리즘 ${ }^{[13]}$ 을 이용하였다. SAX 알고리즘은 A F까지의 알파 벳 문자열로 2 배 축소 변환을 한 뒤 미리 정의된 피크 를 나타내는 문자열('A' - 'J' - 'G' - 'B' - 'A')과 비교하 는 형태로 이루어진다. PPG 데이터에 SAX 알고리즘 을 적용하고 피크를 표현하면 그림 7과 같다.

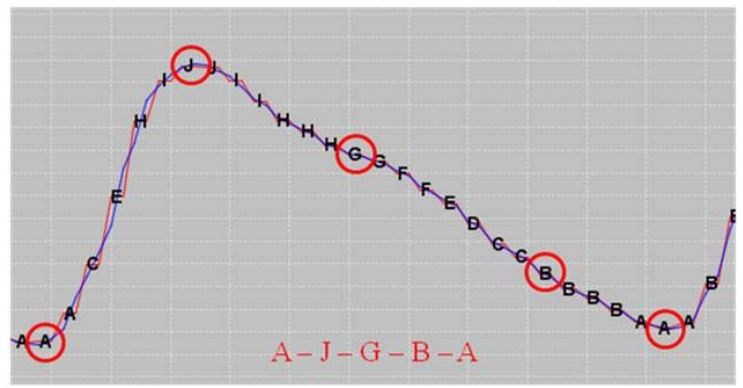

[그림 7] 알파벳으로 표현한 PPG 데이터의 Peak

이렇게 변환된 알파벳 문자열 부분 중 피크를 나타 내는 알파벳 문자열을 Java의 정규식 (Regular Expression)을 이용하여 검출하는 기법을 적용하였다. 그 리고 보다 높은 정확성을 위해 벡터 기반 유사성 검색 을 수행하였다. 변환 문자열을 $\mathrm{P}=(\mathrm{P} 1, \mathrm{P} 2, \cdots, \mathrm{Pn})$ 라 하 고 패턴 문자열을 $\mathrm{Q}=(\mathrm{Q} 1, \mathrm{Q} 2, \cdots, \mathrm{Qn})$ 라 할 때 아래의 식 1 을 이용하여 벡터기반 유사성 검색을 수행한다.

$$
\cos (\theta)=\frac{P \cdot Q}{\|P\|\|Q\|}
$$

\section{2. 주파수 도메인 분석}

주파수 도메인 분석에서는 자율 신경계 균형도를 분석할 수 있다. 이를 수행하기 위해서는 먼저 시간 도메인 데이터를 주파수 도메인 데이터로 변형하여야 한다. 먼저 시간 도메인 분석에서 심박수를 산출하기 위한 피크를 찾는다. 그리고 심박동간의 $1 / 1000$ (millisecond)초 단위로 시간을 측정하여 고속 푸리에 변환(FFT, Fast Fourier Transform)을 함으로써 주파수 도메인으로 변형 가능하다. 이렇게 변형된 주파수 도 메인 데이터를 파워스펙트럼 그래프로 표현하면 그림 8 과 같다. 주파수 도메인 데이터는 수치에 따라 Very Low Frequency(VLF: 0 0.04), Low Frequency(LF: 0.04 0.15), High Frequency(HF: 0.15 0.4)로 분류되고 이 를 도합하여 Total Power (TP: $0 \sim 0.4$ )라 표현한다. 분 할되는 도메인 데이터 수치 중 $\mathrm{HF}$ 이상의 대역 $(0.4$ 이 상)은 분석 데이터에서 제외한다. 이 과정에서 얻어진 $\mathrm{LF}$ 를 $\mathrm{HF}$ 로 나누면 $\mathrm{LF}$ 와 $\mathrm{HF}$ 의 비율이 계산되고 이를 자율 신경계 균형도 분석이라 한다.

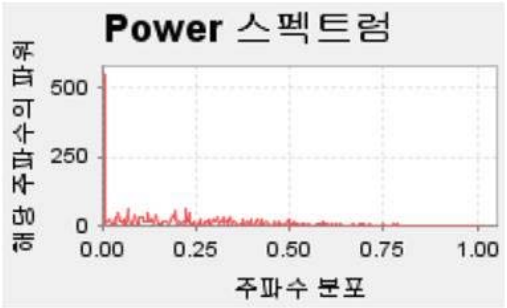

그림 8] FFT 파워스펙트럼 그래프

\section{3. 가속도 맥파 파형 분석}

가속도 맥파 파형 분석에서는 사용자의 혈관 상태 를 분석할 수 있다. 가속도 맥파 파형 분석을 수행하 기 위해서는 PPG 데이터를 2 차 미분하여 가속도 맥파 파형인 APG 데이터로 변형하여야 한다. 변형된 $\mathrm{APG}$ 데이터는 그림 9와 같다. 


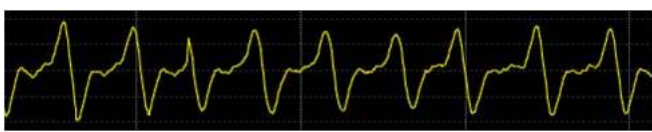

[그림 9] 가속도 맥파 파형 데이터

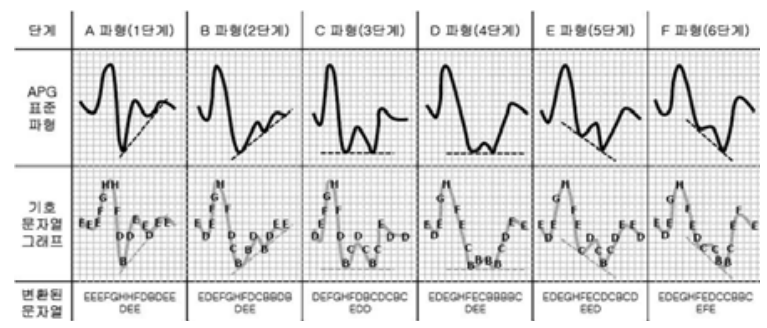

[그림 10] 표준 맥파 파형

PPG 데이터를 이용하여 변형된 APG 데이터는 그 림 10 과 같이 미리 정의된 $\mathrm{A} \sim \mathrm{F}$ 타입의 표준 맥파 파 형과 비교하여 측정된 혈관 상태를 분석하게 된다. 비 교 방식은 PPG 데이터에서 피크를 검출하는 과정과 동일하다. $\mathrm{SAX}$ 알고리즘에 $\mathrm{APG}$ 데이터를 적용하여 $\mathrm{PAA}$ 데이터로 변환한다. 그리고 Java의 정규식과 벡터 기반 유사성 검색을 수행하여 가장 유사한 표준 맥파 파형을 추출한다.

\section{3. 분석 데이터 저장 및 출력}

3 단계 분석 데이터 저장 및 출력에서는 2 단계에서 분석된 데이터를 한눈에 알아볼 수 있는 분석 그래프 로 표현한다. 그리고 출력 가능한 특정 형식으로 저장 하며, 사용자가 출력을 원할 경우 출력물로 제공한다.

\section{III. 결과}

본 논문에서 구현한 PPG 센서를 이용한 실시간 생 체신호 모니터링 및 분석 시스템의 구현은 윈도우XP 환경에서 개발언어 Java(JDK 1.6), DHTML를 사용하였 다. 본 시스템은 사용자가 PPG 센서를 이용하여 자신 의 신체 상태를 쉽고 간편하게 측정하기 위해 설계되 었다. 시스템 구현은 의학적 지식이 없는 일반 사용자 가 사용할 수 있도록 간편한 인터페이스를 제공하도 록 구성하였다. 생체신호 데이터 수집 시 장시간 측정 할 경우 분석 결과의 신뢰도를 높일 수 있다. 하지만 본 시스템에서는 분석에 필요한 최소 시간만을 측정
하여 사용자에게 결과를 제공함으로써 편리성에 좀 더 초점을 맞추었다. PPG 센서를 본 프로그램과 연동 하여 사용하기 위해서는 UART Communication 시스템 드라이버가 필요하다. 본 시스템 드라이버는 프로그램 설치 파일을 이용하여 실시간 생체신호 모니터링 및 분석 시스템을 설치하는 경우 함께 설치되도록 하였 다.

설치 완료 후 $\mathrm{PPG}$ 센서를 $\mathrm{PC}$ 에 연결하고 프로그 램을 구동하면 프로그램 메인 인터페이스가 나타난다. 프로그램 메인 인터페이스의 하단에는 사용자가 이용 할 수 있는 각 메뉴가 존재한다. 만약 프로그램을 최 초 구동 하였다면, $\mathrm{PPG}$ 센서와의 통신을 위한 포트를 설정해 주어야 한다. 설정 메뉴에서 통신 설정을 마친 뒤 데이터를 저장하면 이후 프로그램 구동 시 저장된 정보를 불러와 프로그램에 자동 설정한다. 사용자 메 뉴에서는 사용자의 등록 및 선택 과정이 이루어지며, 사용자의 등록 및 선택 과정을 거친 뒤에 해당 사용자 에 대한 검사, 검사 기록 메뉴를 사용할 수 있다.

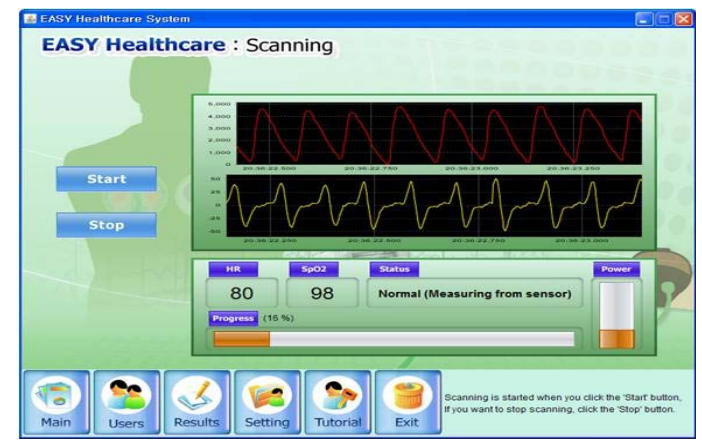

[그림 11] 사용자 인터페이스

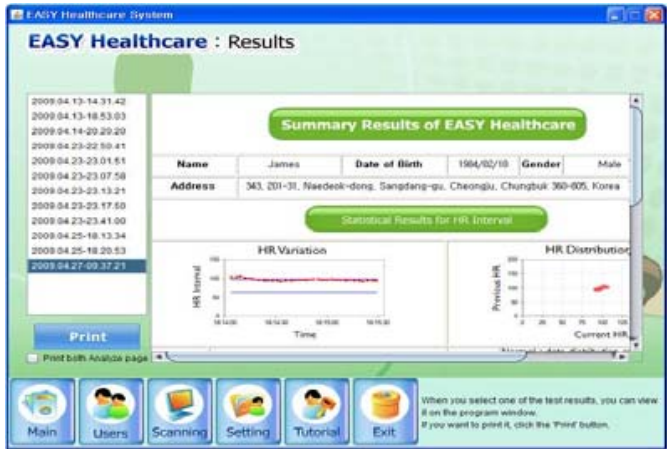

[그림 12] 검사결과 이력조회 화면 
그림 11은 설정 과정, 사용자 등록 및 선택 과정을 거친 뒤 검사를 수행하고 있는 사용자 인터페이스 화 면이다. 사용자 인터페이스 화면에서 상태 바의 그래 프가 $100 \%$ 로 완료될 경우 검사가 종료되며, 자동 분석 되고 특정 양식으로 저장된다.

그림 12 는 분석된 결과를 나타내는 검사 결과에 대 한 이력조회 인터페이스 화면으로 사용자는 자신의 과거 및 현재 측정 정보를 살펴볼 수 있다. 이 측정정 보는 출력 가능한 특정 형식으로 저장하고 사용자가 출력을 원할 경우 출력물로 제공되며, 분석 데이터의 출력물은 그림 13 과 같다.

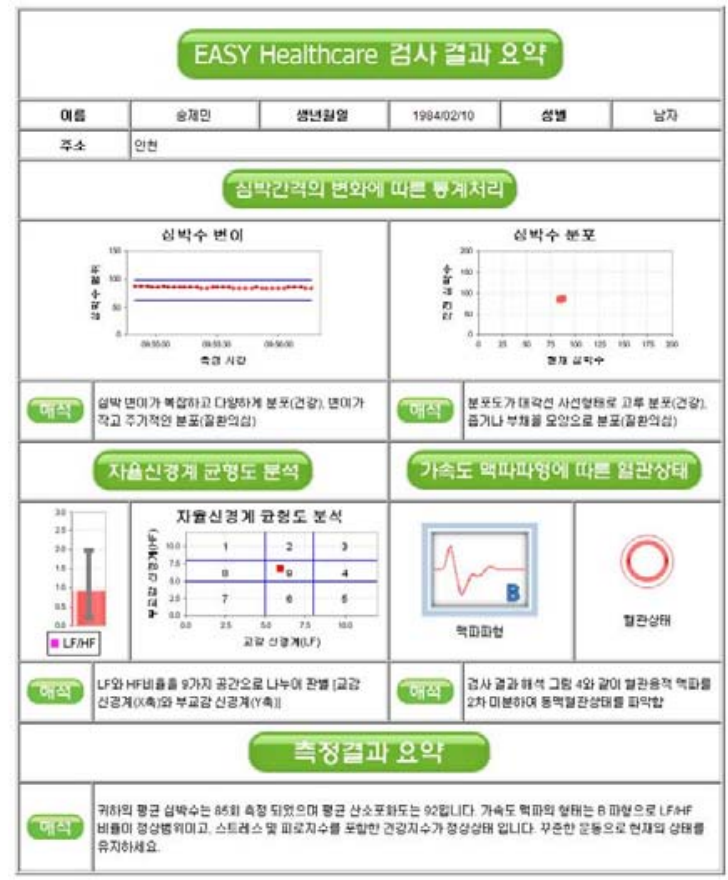

[그림 13] 분석 데이터 출력물

\section{IV. 결론 및 고찰}

본 논문에서는 PPG 센서를 이용하여 심혈관질환의 조기 예측 시스템의 설계 및 구현하였다. 기존의 알려 진 생체신호 분석기법을 프로그램으로 적용하여 센서 모듈을 컴퓨터 USB에 연결하고 프로그램을 설치만 하 면 일반 사용자가 손쉽게 자가 측정이 가능한 시스템 을 구축하였다. 제안한 시스템은 앞으로 의료 및 실버 케어 등의 분야에서 널리 사용될 u-헬스케어 시스템의
기초가 되는 시스템을 구축하였다는데 그 의미가 크 다고 할 수 있다. 현재는 PPG 센서만을 이용하여 기본 적인 생체신호 분석기법을 적용하였지만, 다양한 센서 를 이용하여 생체신호를 수집하고 수면 중 혹은 운동 중 측정 등 다양한 상태의 생체신호를 수집하여 분석 한다면 좀 더 포괄적이고 심층적인 분석 시스템으로 향상시키는 것이 가능할 것으로 기대된다. 그리고 향 후 연령별, 남녀, 심혈관 질환보유자를 대상으로 실험 하여 시스템의 유용성을 검증할 예정이다.

\section{감사의 글}

이 연구는 지식경제부 산업원천기술개발사업 (10037283), 중소기업청에서 지원하는 2010년도 산학연 공동기술개발사업..00042150-1)과 2010년 교육과학기술 부 지원으로 수행되었음(지역거점연구중심사업단/충 북BIT연구중심대학사업단).

\section{참고문헌}

[1] http://www.nhlbi.nih.gov/health/dci/Browse/Heart.html

[2] 통계청, “2009년 생명표”, pp. 16-53, 12월, 2009.

[3] 김용진, 장혁재, 이상철, 최연현, 범희승, 홍명기, “심혈관질환 진단의 최신 영상 기법”, 엠엠케이커뮤니케이션, 제12권, 제1호, pp. 1-55, 2월, 2010.

[4] Nichols WW, "Clinical measurement of arterial stiffness obtained from noninvasive pressure waveforms” Am J Hypertens, 제18권, pp. 3-10, 1월, 2005

[5] Allen J, "Photoplethysmography and its application in clinical physiological measurement”, Physiol Meas, 제28권, 제3호, pp. 1-39, 2월, 2007.

[6] Oliver JJ, Webb DJ, "Noninvasive assessment of arterial stiffenss and risk of atherosclerotic events", Arterioscler Thromb Vasc Biol, 제23권, pp. 554-566, , 2월, 2003.

[7] Takazawa K, Tanaka N, Fujita M, Matsuoka O, Saiki T, Aikawa M, Tamura S, Ibukiyama C, "Assessment of vasoactive agents and vascular aging by the second derivative of photoplethysmogram waveform”, Hypertension, 제32권, 제2호, pp. 365-370, 8월, 1998.

[8] Alnaeb ME, Alobaid N, Seifalian AM, Mikhailidis DP, Hamilton G, "Optical techniques in the assessment of peripheral arterial disease”, Curr Vasc Pharmacol, 제5권, 제1호, pp. 53-59, 1월, 2007. 
[9] 진계환, “가속도계를 이용한 상황인식시스템”, 충북대학교 박사학위논문, 2006

[10] Enkhdorj Rentsendorj, "심장혈관질환의 고위험군에서 위팔-발목 맥파속도와 복부 대동맥 경직도 지표간의 상관관계”, 한양대학교 석사학위논문, 2009

[11] 공형윤, 이정석, 서상원, 조성환, 김상현, 채원석, 진희철, 김용익, "뇨병 환자에서 Rocuronium이 심박수 변이도에 미치는 영향”, Korean J Anesthesiol, 제57권, 제2호, pp. 165-169, 8월, 2009.

[12] Keogh EJ, "Exact indexing of dynamic time warping” In VLDB 2002, Proceedings of 28th International Conference on Very Large Data Bases, pp. 20-23 8월, 2002.

[13] Lin J, Keogh E, Lonardi S, Chiu B, "A Symbolic Representation of Time Series, with Implications for Streaming Algorithms", In proceedings of the 8th ACM SIGMOD Workshop on Research Issues in Data Mining and Knowledge Discovery, 2003 